\title{
Echinoparyphium limosorum n. sp. (Trematoda: Echinostomatidae) from Black- tailed Godwit, Limosa limosa (Aves, Charadriiformes) in Slovakia
}

\author{
J. K. MACKO ${ }^{1}$, M. ŠPAKULOVÁ ${ }^{1 *}$, A. MACKOVÁ ${ }^{2}$ \\ ${ }^{1}$ Parasitological Institute SAS, Hlinkova 3, 04001 Košice, Slovakia, E-mail: spakulma@saske.sk; ${ }^{2}$ Pavol Jozef Šafárik \\ University in Košice, Faculty of Science, Mánesova 16, 04154 Košice, Slovakia
}

\begin{abstract}
Summary
Echinostomatid trematode Echinoparyphium limosorum n. sp. from the charadriiform bird Limosa limosa is described on basis of morphometrical study of museum material. The new species is characterized by medium-sized body up to $4.9 \mathrm{~mm}$ long, reniform head collar up to 511 wide, armed with $48-51$ collar spines up to $91 \mu \mathrm{m}$, arranged in double row. The new species is largely similar to Echinoparyphium recurvatum, however, the most remarkable difference lays in the higher number of collar spines which are $48-51$ in E. limosorum n. sp. but 45 in E. recurvatum. The authors discuss relative impact of numerical generic characters and propose an amending of the diagnosis of the genus Echinoparyphium given by Kostadinova (2005) as follows: Collar spines up to 51, sharply pointed, all in double row.
\end{abstract}

Keywords: Echinoparyphium limosorum; Trematoda; Limosa limosa; Charadriiformes; Slovakia; new species

\section{Introduction}

The research of helminths parasitic in migratory charadriiform birds which had been conducted in Slovakia from fifties to seventies of the last century, often revealed new information on alien parasites imported by their bird hosts from southern wintering habitats to Central Europe (e.g. Macko et al., 2008a, b). Black-tailed Godwit Limosa limosa, population breeding in eastern Europe, i.e. in Ukraine, Belarus, Russia and, according to Ferianc (1977) very probably also in eastern Slovakia, mainly winters in East Africa as reported in the "Management Plan for Black-tailed Godwit Limosa limosa 2007 - 2009" under the program Natura 2000 of The European Commision (ec.europa.eu/environment/nature/conservation/wildbirds/h unting/docs/black_tailed_godwit.pdf). Nowadays, the Black-tailed Godwit is regarded a threatened species and the mentioned EC Management Plan is aimed to restora- tion of its populations in Europe. Therefore, recent collections of intestinal parasites of the bird are impracticable; however, re-evaluations of museum material often lead to a discovery of new non-described taxa.

The recent paper describes a new echinostomatid trematode species Echinoparyphium limosorum n. sp. on basis of 5 specimens from a L. limosa host. Since the year 1962, the material has been deposited as permanent slides in the personal collection of the first author. The paper proposes an amending of the generic diagnosis of Echinoparyphium.

\section{Material and Methods}

Five trematodes were recovered from a single host bird Black-tailed Godwit shot at the Dvor Keresztúr near the villages Pavlovo and Svätá Mária at the River Bodrog, southeastern Slovakia, in May 1962. The isolated trematodes were compressed, fixed in alcohol-formol-acetic acid (AFA), stained in Semichon's carmine and mounted in Canada balsam. Morphological traits were studied and measured using the microscope Olympus equiped with digital camera. Measurements are in micrometres $(\mu \mathrm{m})$ except where otherwise indicated.

Except of detecting traditionally used morphological features, following indices were calculated according to Kostadinova (2005): BW\% - the shape of body assessed by the maximum body-width as a proportion of the body-length; FO\% - the relative length of the forebody (i.e. the distance from the anterior extremity to the centre of ventral sucker) expressed as a proportion of the body-length; U\% - the relative uterine length (i.e. distance between the ovary and the posterior margin of the ventral sucker) expressed as a proportion of body-length; $\mathrm{T} \%$ - relative length of the post-testicular field (i.e. distance from the posterior testis margin to the posterior extremity) estimated as a proportion of body-length. 


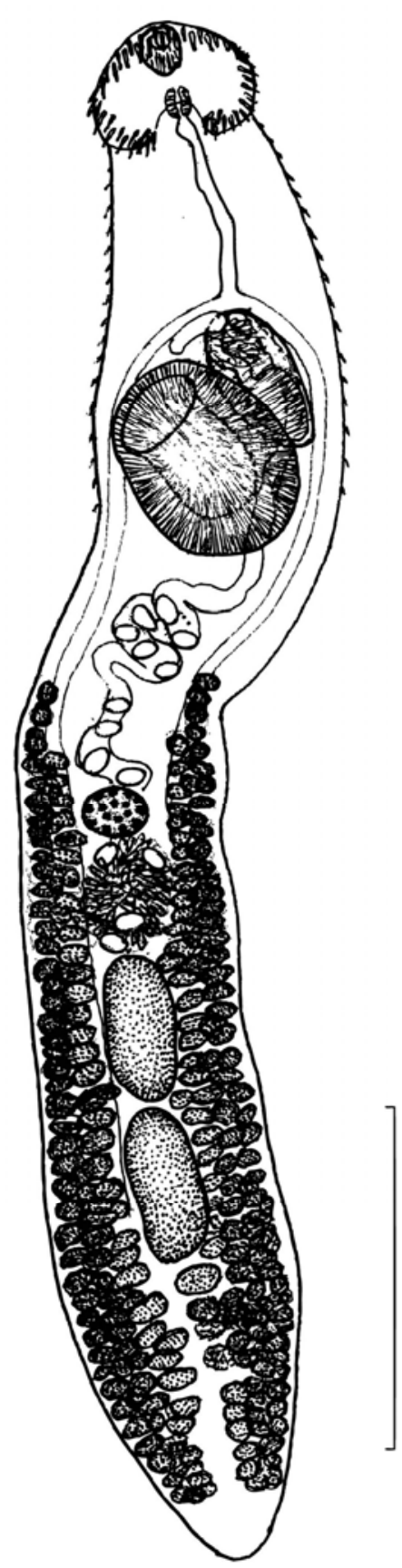

Fig. 1 Echinoparyphium limosorum n. sp. Holotype. Scale-bar $1 \mathrm{~mm}$.

\section{Results}

Echinoparyphium limosorum $\mathrm{n}$. sp.

Type-host: Linosa limosa (L.) (Aves, Charadriiformes, Scolopacidae).

Type-locality: Dvor Keresztúr, River Bodrog (eastern Slovakia), $48^{\circ} 42^{\prime}, 21^{\circ} 87^{\prime}$.

Site of infection: Small intestine.

Prevalence: 1 bird host.

Material studied: Holotype No. 380/62c; Paratypes: 380/62i - 4 specimens. All 5 specimens complete, gravid, paratypes with a few collar spines falling off. The material is deposited in the Helminthological collection at the Parasitological Institute SAS, Hlinkova 3, 04001 Košice, Slovakia.

Etymology: Specific name of the trematode has been derived from the name of the bird type host.

Description (Figures $1-3$ ). Data in brackets represent holotype characteristics.

Body elongate, with maximum width at level of ventral sucker. Body length 3862 - 4913 (4 684); maximum body width at the level of ventral sucker $628-739$ (785), BW\% $=15.2-16.8$ (16.8). Body width at level of testes $549-$ 706 (699). Forebody $989-1350$ (1 311), FO\%= $23.1-$ 28.8 (28.0), ventrally slightly bent. Tegument armed with small spines reaching level of posterior margin of ventral sucker, maximum length 15 at level of intestinal bifurcation (Fig. 1).

Head collar reniform, 363 - 511 (511) wide, with ventral ridge. Collar spines $48-51$ (51, Fig. 2), in double row. Ventral spines 6 in number, $67-91 \times 12-17(67-83 \times$ 15.5 - 17), lateral spines 49.4 - 69 x 11-14 (56- 67 x 10.4 - 13), dorsal oral spines $39-68 \times 9-12(39-65 \times 10.4-$ 13), dorsal aboral spines longer, $64-75$ x $11-14.3$ (68 73 x 13 - 14). A single specimen show extremely small spines probably due to their vertical orientation.

Oral sucker spherical or subspherical (in 1 specimen pearshaped), 111 - 164 × 109 - 146 (164 x 140). Ventral sucker muscular, $484-640 \times 421-628(640 \times 523)$, its middle located 956 - 1350 (1313) from anterior body margin. Prepharynx of variable length, up to 78 (26) long. Pharynx muscular, elongate-oval, 91 - 111 x $60-90$ (106 $x$ 87). Oesophagus not very distinct, about 530 long. Intestinal bifurcation anterior to ventral sucker, intestinal

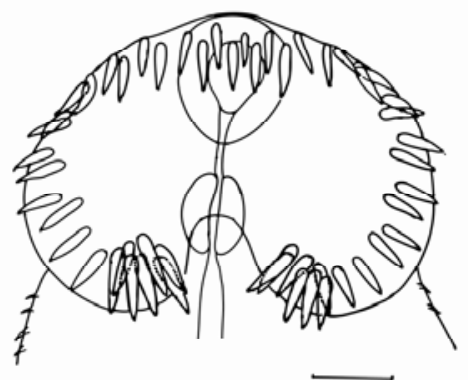

Fig. 2 Echinoparyphium limosorum n. sp. Holotype. Head collar with 51 collar spines. Scale-bar $100 \mu \mathrm{m}$.

branches uncertain.

Testes tandem, elongate-oval, smooth, contiguous or nearly contiguous, located in second body half; anterior testis $444-543 \times 234-273(468 \times 249)$, posterior testis $475-577$ × $203-271(483$ x 241). Post-testicular region 706 - 957 (909.5) long, $\mathrm{T} \%=16.5-20.3$ (19.4) of body length. Cirrus-sac muscular, elongate-oval, $367-413 \mathrm{x}$ $156-280(413 \times 280)$, antero-dorsal to ventral sucker, reaching from intestinal bifurcation to middle of ventral sucker. Internal seminal vesicle saccular, simple. Pars prostatica developed, distinct in anterior third of cirrus-sac. Cirrus tubular, unarmed, of unclear length. In region of 
genital pore, funnel-like opening resembling more or less muscular sphincter, is located.

Ovary spherical or nearly oval, comact, median, pre-equatorial in 2 specimens and equatorial in 3 specimens, $156-$ $218 \times 191-226(156 \times 204)$ in diameter. Distance from ventral sucker to ovary $659-989(769), \mathrm{U} \%=15.5-18.7$ (16.4) in 4 specimens and $U \%=23.1$ in 1 specimen. Mehlis' gland large, median, immediately pretesticular, spherical or elongate-oval, 273 - 468 × 226 - 351 (390 x 304). Uterus moderately developed, with few intercaecal loops between ovary and ventral sucker. Eggs not numerous, 14 - 42 (14). Egg size depending on their number: $88-114 \mathrm{x}$ $52-69(104-113 \times 61-69)$ in 4 specimens with $14-19$ eggs, $68-86 \times 53-60$ in a specimen with 42 mostly deformed eggs. Vitellarium follicular with follicules up to 78 - $86 \times 133-152$, distributed in 2 lateral fields between level of middle uterus and posterior extremity, in posttesticular region fields not confluent in 3 specimen, nearly confluent in 1 specimen and confluent in 1 specimen. Excretory vesicles not observed, excretory pore terminal.

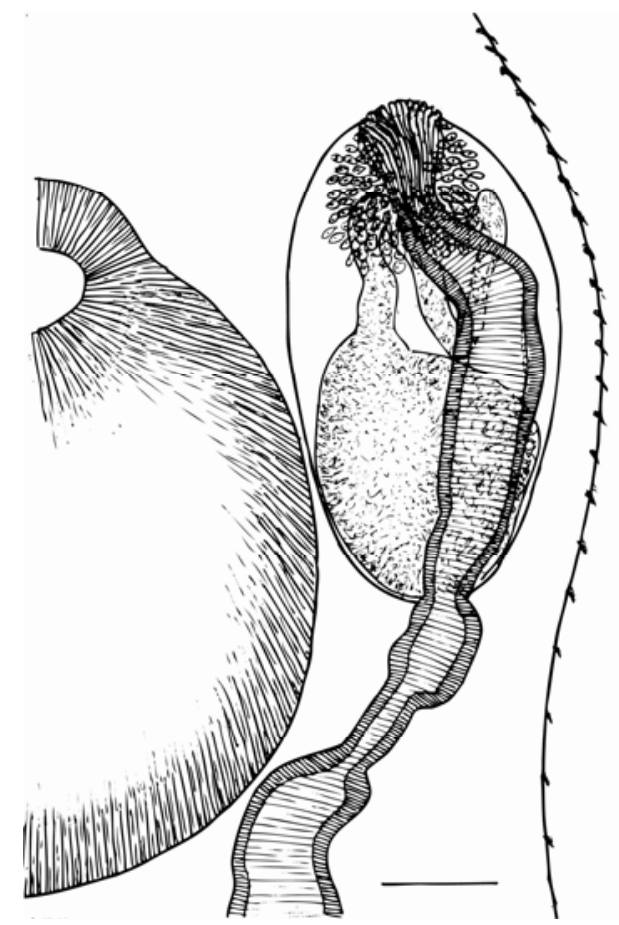

Fig. 3 Echinoparyphium limosorum n. sp. Paratype. Terminal part of genital ducts with not protuberant cirrus, lateral view. Scale-bar $100 \mu \mathrm{m}$.

\section{Remarks}

The above characteristics correspond with the generic diagnosis of the Echinoparyphium Dietz, 1909, as stated by Kostadinova (2005), including the proposed indices $\mathrm{BW} \%, \mathrm{FO} \%$ and $\mathrm{T} \%$. The exceptions lie in 1) higher number of collar spines $(48-51)$ in the new species, versus 29 -45 in the generic diagnosis, 2) slightly longer uterus in a single specimen $(\mathrm{U} \%=23,1$ versus $3-20$ in generic diagnosis) due to an apparent damage of the anterior part of the specimen, 3) discrepancy in number and size of eggs between 4 specimens containing $14-19$ larger eggs and 1 specimen with 42 much smaller eggs; this might be easily interpreted in terms of "crowding effect" (see the similar feature described in Dicrocoelium dendriticum by Macková et al. (1997), and 4) higher level of variation in the distribution of vitelline fields in post-testicular region which either are separated or are confluent.

\section{Differential diagnosis}

As the number of collar spines of echinostomatids is regarded as one of the weightiest differential generic features, we have compared the new species not only with the Echinoparyphium congeners which according to the latest generic diagnosis possess maximum of 45 spines (Kostadinova, 2005), but also with additional species of the relative genera having from 43 to 55 collar spines.

In Black-tailed Godwit, several Echinoparyphium species were found in Central Europe (Hudec, Št'astný et al., 2005). They are E. aconiatum (Dietz, 1904) (having 37 collar spines), E. cinctum (Rudolphi, 1802) (43 spines), E. clerci Skrjabin, 1915 (41 spines), E. mordwilkoi Skrjabin, 1915 (45 spines), E. paracinctum Bykhovskaya-Pavlovskaya, 1953 (43 spines) and E. recurvatum (Linstow, 1873) (45 spines).

Out of the above mentioned Echinoparyphium parasites of $L$. limosa, only the species E. recurvatum and E. mordwilkoi possess the higher number of 45 collar spines. The new species $E$. limosorum is relatively very similar to $E$. recurvatum. They differ each other mainly in 1) the number and size of collar spines (48 - 51 in the number, up to $91 \mu \mathrm{m}$ long in E. limosorum vesus 45 and up to $76 \mu \mathrm{m}$ in E. recurvatum (see Kanev et al., 2008); 2) morphology of vitelline fieds in the post-testicular region which may be confluent in A. limosorum but not in E. recurvatum.

Regarding E. mordwilkoi, Kanev et al. (2008) considered this species belonging to the E. recurvatum species complex. Except of the difference in the number of spines (45 versus $48-51$ in the new species), E. mordwilkoi has the smaller body size (up to 2.8 x $0.54 \mathrm{~mm}$ versus $3.8-4.9 \mathrm{x}$ $0.6-0.7 \mathrm{~mm}$ in the new species) and the relatively long post-testicular part T \%=31.4, as counted from the drawing of E. mordwilkoi published by Skrjabin and Bashkirova (1956), versus T \% $=20.3$ in the new species.

The congeners E. aconiatum, E. cinctum, E. clerci and E. paracinctum have not only the lower number of collar spines but also different size of the body and internal organs.

Skrjabin and Bashkirova (1956) enumerated also the species Echinoparyphium petrowi Nevostrueva, 1953 having 49 collar spines. However, the species has been later designated as the type species of the newly established genus Neoacanthoparyphium Yamaguti, 1958 (Yamaguti, 1958) and it differed from E. limosorum n. sp. aparently in the minute size of the body up to $0.8 \mathrm{~mm}$, small organs and collar spines of very distinct size.

Considering Echinostoma Rudolphi, 1809 species, only E. academica Skrjabin, 1915 was found even in Back-tailed Godwit in various regions (Bychovskaya-Pavlovskaya, 1962; Hudec and Št'astný, 2005). It differs from L. limo- 
sorum n. sp. by 1) much larger body up to $8.5 \mathrm{x} 1.2 \mathrm{~mm}$; 2) lower number of 43 collar spines; 3 ) characteristic scalelike type of tegumental armament and 4) well developed uterus with numerous eggs.

There are another bird Echinostoma species described from Europe and Asia, possessing similar number of collar spines as the new species: E. chloropodis Zeder, 1800 (47 spines), E. coecale Murashkinzev, 1937 (49 spines), E. corvi Yamaguti, 1935 (47), E. sarcinum Dietz, 1909 (47) and E. travassosi Skrjabin, 1924 (47) (Skrjabin \& Bashkirova, 1956). However, all of them are characterized by rather large body size, well developed uterus, numerous eggs which together with other features differentiate them clearly from E. limosorum n. sp. Within the genera Echinostoma and Euparyphium, there are some other species of medium-sized body having around 50 collar spines, parasitic various bird and mammal hosts from South America, Australia and the Phillippines. However, all the species differ from E. limosorum n. sp. by many diagnostic markers.

\section{Discussion}

An identification of many echinostomatid species and genera remains still problematic due to the fact that distinct differential markers still do not exist on the morphological level. For instance, Yamaguti (1958) differentiated two groups of genera, one comprising Echinostoma and the other Echinoparyphium, using uncertain characteristics: "Uterus more or less long, with numerous eggs" versus "Uterus rather short with not numerous eggs". Therefore, Kostadinova (2005) tried to find more accurate and relevant criteria which would help to distinguish echinostomatid genera. Apart from the traditionally used features like the degree of development and the morphology of the collar, the number, shape, arrangement and relarive size of the collar spines, the morphology of the male terminal genitalia, etc., Kostadinova (2005) proposed four additional indices, each assessed as a proportion of the character to the body length (see Material and Methods). On one hand, such relative criteria decrease the variation in real size of morphological features, however, the boundary values of indices might overlap when comparing extremely varying populations or species including those of discussed genera Echinoparyphium, Echinostoma, and Euparyphium. Moreover, newly described species may be characterized by morphological markers which in general fit with some generic diagnosis but a single feature surpasses it.

The recently described E. limosorum n. sp. demonstrates the above mentioned problems. All but one characteristic correspond with the generic diagnosis of Echinoparyphium; the exception is represented by the higher number of collar spines than 45, until now the maximum number within the genus Echinoparyphium (Kostadinova, 2005). It is evident, that the strict numerical characters of individual echinostomatid genera should be modified in some cases. Therefore, we suggest amending the generic diagnosis as follows: Collar spines up to 51, sharply pointed, all in double row.

Similar situation might appear already when a new species are described and their generic affiliation seems to be unclear. It is apparent that some room for subjective decision should be left to specialists experienced in alfha taxonomy, especially in a case that the museum material is evaluating without any opportunity to use additional, e.g. molecular approaches (see Kostadinova et al., 2003). Besides, especially valuable are recent re-descriptions of rarely found species even though they were only on morphological basis and omit molecular analyses (e.g. Santoro et al., 2008).

Many problems lie in an uncertainty of the generic category as discussed by Macko et al. (2008a, b). In any case, it is inevitable to assemble and publish papers summarizing current species spectrum of individual genera which supplement the current keys directed only to lists of genera and higher taxa (Gibson et al., 2002, Jones et al., 2005, Bray et al., 2008). Fortunately, such revisions are currently appearing also within the traditionally very problematic family Echinostomatidae (Kostadinova \& Gibson, 2002, Faltýnková et. al., 2008a, b).

\section{Acknowledgements}

The study was supported by the Grant Agency of the Slovak Republic VEGA, project No. 2/7192/27 and the project of the Slovak Research and Development Agency APVV-51-062205.

\section{References}

BrAY, R. A., GiBSON, D. I., JonES, A. (2008): Keys to the Trematoda, Volume 3. CABI Publishing and Natural History Museum London, Wallingford, 848 pp.

BYKHOVSKAYA-PAVLOVSKAYA, I. E. (1962): Bird trematodes of fauna USSR, ecological and geographical survey. Publ. House AS USSR, Moskva, Leningrad. (in Russian)

FaltÝnková, A., GiBSOn, D. I., Kostadinova A. (2008a): A revision of Patagifer Dietz, 1909 (Digenea: Echinostomatidae) and a key to its species. Syst. Parasitol., 70: $159-183$

FaltÝnKovÁ, A, Gibson, D.I., Kostadinova, A. (2008b) A revision of Petasiger Dietz, 1909 (Digenea: Echinostomatidae) and a key to its species. Syst. Parasitol., 71: $1-40$

FERIANC, O. (1977): Birds of Slovakia. I. Publ. House VEDA, Bratislava. (In Slovak)

GiBson, D. I., JONES, A., BRAY, R. A. (2002): Keys to the Trematoda, Volume 1. CABI Publishing and Natural History Museum London, Wallingford, $521 \mathrm{pp}$.

HudEC, K., ŠŤASTNÝ, K. et al. (2005): Fauna CR: Birds Aves. Volume II/2. Publ. House Academia, 2nd revised edition, Prague. (In Czech)

Jones, A., Bray, R. A., GiBson, D. I. (2005): Keys to the Trematoda, Volume 2. CABI Publishing and Natural History Museum London, Wallingford, $745 \mathrm{pp}$.

KANEV, I., FRIED, B., RADEV, V. (2008): Identification problem with species in the Echinoparyphium recurvatum 
complex from physid snails in the USA. Parasitol. Res. 103: 963 - 965

Kostadinova, A. (2005): Family Echinostomatidae Looss, 1899. In Jones, A., BRAY, A., GIBSON, D. I. (Eds.): Keys to the Trematoda Volume 2. CABI Publishing and The Natural History Museum, London p. 9 - 64

Kostadinova, A., GiBson, D. I. (2002) Isthmiophora Luhe, 1909 and Euparyphium Dietz, 1909 (Digenea: Echinostomatidae) re-defined, with comments on their nominal species. Syst. Parasitol., 52: $205-217$

Kostadinova, A., Herniou, E. A., Barrett, J., LiTTLEWOOD, D. T. J. (2003): Phylogenetic relationships of Echinostoma Rudolphi, 1809 (Digenea: Echinostomatidae) and related genera re-assessed via DNA and morphological analyses. Syst. Parasitol., 54, 3, $159-176$

MackovÁ, A., MackO, J. K., ŠPAKUlOVÁ, M. (1997): On the variability of Dicrocoelium dendriticum (Rudolphi, 1819) in domestic and free-living animals. VI. Variability of eggs of $D$. dendriticum from Slovakia and Algeria. Helmintologia, 34: 27 - 33
Macko, J. K., HanzelovÁ, V., DudiňÁK, V. (2008a): Fuhrmanolepis dubinskyi n. sp. (Cestoda: Dilepididae) from woodcock Scolopax rusticola (L.) (Aves, Charadriiformes) in Slovakia. Helminthologia, 45: 130 - 133

MACKO, J. K., MACKOVÁ, A., SABOlOVÁ-BARLÁKOVÁ, S. (2008b): Fuhrmanolepis beskydensis n. sp. (Cestoda: Dilepididae) from woodcock Scolopax rusticola L. (Aves, Charadriformes) in Slovakia with comments on systematics and nomenclature of the genus Fuhrmanolepis Spassky and Spasskaya, 1965. Helminthologia, 45: $173-180$.

SAntoro, M., Brandmayr, P., Greiner, E. C., Morales, J. A., Rodríguez-OrTíz, B. (2008): Redescription of Charaxicephaloides polyorchis Groschaft et Tenota, 1978 (Digenea: Pronocephalidae from the freen turtle Chelonia mydas in Costa Rica. Helmintologia, 46: 97 - 99

SKRJABIN, K. I., BASHKIROVA, E. Y. (1956): Family Echinostomatidae. Osnovy Trematodologii, 12, 53 - 930 (In Russian)

YAMAGUTI, S. (1958): Systema helminthum. Vol. I. The digenetic trematodes of vertebrates. New York: Interscience Publishers.

ACCEPTED August 23, 2009 